\title{
Convective Storm Initiation in a Moist Tropical Environment
}

\author{
MARIA ANDREA Lima \\ Instituto de Pesquisas Meteorológicas/UNESP, Bauru, São Paulo, Brazil \\ JAMES W. WILSON \\ National Center for Atmospheric Research, * Boulder, Colorado
}

(Manuscript received 5 June 2007, in final form 11 October 2007)

\begin{abstract}
Radar and satellite data from the Tropical Rainfall Measuring Mission-Large-Scale BiosphereAtmosphere (TRMM-LBA) project have been examined to determine causes for convective storm initiation in the southwest Amazon region. The locations and times of storm initiation were based on the National Center for Atmospheric Research (NCAR) S-band dual-polarization Doppler radar (S-Pol). Both the radar and the Geostationary Operational Environmental Satellite-8 (GOES-8) visible data were used to identify cold pools produced by convective precipitation. These data along with high-resolution topographic data were used to determine possible convective storm triggering mechanisms. The terrain elevation varied from 100 to $600 \mathrm{~m}$. Tropical forests cover the area with numerous clear-cut areas used for cattle grazing and farming. This paper presents the results from 5 February 1999. A total of 315 storms were initiated within $130 \mathrm{~km}$ of the S-Pol radar. This day was classified as a weak monsoon regime where convection developed in response to the diurnal cycle of solar heating. Scattered shallow cumulus during the morning developed into deep convection by early afternoon. Storm initiation began about 1100 LST and peaked around 1500-1600 LST. The causes of storm initiation were classified into four categories. The most common initiation mechanism was caused by forced lifting by a gust front (GF; 36\%). Forcing by terrain $(>300 \mathrm{~m})$ without any other triggering mechanism accounted for $21 \%$ of the initiations and colliding GFs accounted for $16 \%$. For the remaining $27 \%$ a triggering mechanism was not identified. Examination of all days during TRMM-LBA showed that this one detailed study day was representative of many days. A conceptual model of storm initiation and evolution is presented. The results of this study should have implications for other locations when synoptic-scale forcing mechanisms are at a minimum. These results should also have implications for very short-period forecasting techniques in any location where terrain, GFs, and colliding boundaries influence storm evolution.
\end{abstract}

\section{Introduction}

The objective of this study is to investigate the causes of convective storm initiation and the subsequent evolution during the wet season in the southwest Amazon region. The focus is on a day when large-scale convective storm forcing mechanisms were at a minimum. While the focus of this study is on just 1 day, it is likely representative of many days over the Amazon and

* The National Center for Atmospheric Research is sponsored by the National Science Foundation.

Corresponding author address: Maria Andrea Lima, IPMet/ UNESP, P.O. Box 281, Bauru, São Paulo 17015-970, Brazil.

E-mail: andrea@ipmet.unesp.br other similar tropical areas. Since synoptic-scale fronts are relatively rare in such tropical regions local influences play a significant role in the climatology of initiation and evolution of convection. Understanding these small-scale local processes is important to model simulations in similar tropical and subtropical continental areas since these processes must be resolved by the models if they are to suitably represent the location, timing, and intensity of the convection (Moncrieff et al. 2005; Betts and Jakob 2002).

The opportunity for this study was provided by the Tropical Rainfall Measuring Mission-Large-Scale Biosphere-Atmosphere (TRMM-LBA) field experiment in 1999, when the National Center for Atmospheric Research (NCAR) S-band dual-polarization Doppler radar (S-Pol) was deployed in the state of Rondônia, 
Brazil (Fig. 1). This was the first time a highly sensitive Doppler radar was deployed in the Amazon. S-Pol's ability to detect clear-air boundary layer convergence lines and nonprecipitating cumulus is particularly suitable for studying convective storm initiation and evolution (Wilson et al. 1994).

Section 2 describes previous studies on convection initiation and references studies over the Amazon that document the general precipitation climatology of the region. Section 3 describes the datasets used for this study. Section 4 discusses the frequent observation of cumulus cloud rings and associated gust fronts and their effect on thunderstorm evolution. Section 5 documents thunderstorm initiation and evolution for a single day when large-scale forcing is minimal. In addition the representativeness of this day to other TRMM-LBA days is presented. A summary of results is discussed and incorporated into a conceptual model in section 6 .

\section{Background}

This research was motivated by the following observations during the TRMM-LBA field campaign: first, the early initiation of storms on a given day often appeared random; second, visible satellite observations during the afternoon often showed complex unorganized patterns of convective storms; and, third, the satellite imagery often showed numerous remarkably circular cloud rings. These observations coupled with the knowledge that synoptic forcing was very weak suggested that an excellent opportunity existed to study convective storm initiation and evolution where local influences dominated.

The earlier work of Purdom $(1976,1982)$ with satellite data and Wilson and Schreiber (1986) with radar data showed that the first initiation of thunderstorms on a given day for a variety of locations was often triggered by boundary layer convergence lines. Weckwerth (2000) showed that in Florida the first storms were often triggered by horizontal convective rolls. It has long been known that substantial terrain relief frequently triggers deep convection (Banta and Schaaf 1987; Schaaf et al. 1988), however, it was not generally appreciated that the modest relief in the study area would be a significant triggering mechanism.

Purdom $(1976,1982)$ clearly showed that arcs of cumulus cloud rings associated with thunderstorm outflows would collide with other convergence lines and initiate new storms, often called secondary storms. What was not obvious from initial observation of the satellite and radar data over the Amazon was that the unorganized appearance of much of the afternoon convection was the result of numerous colliding outflows

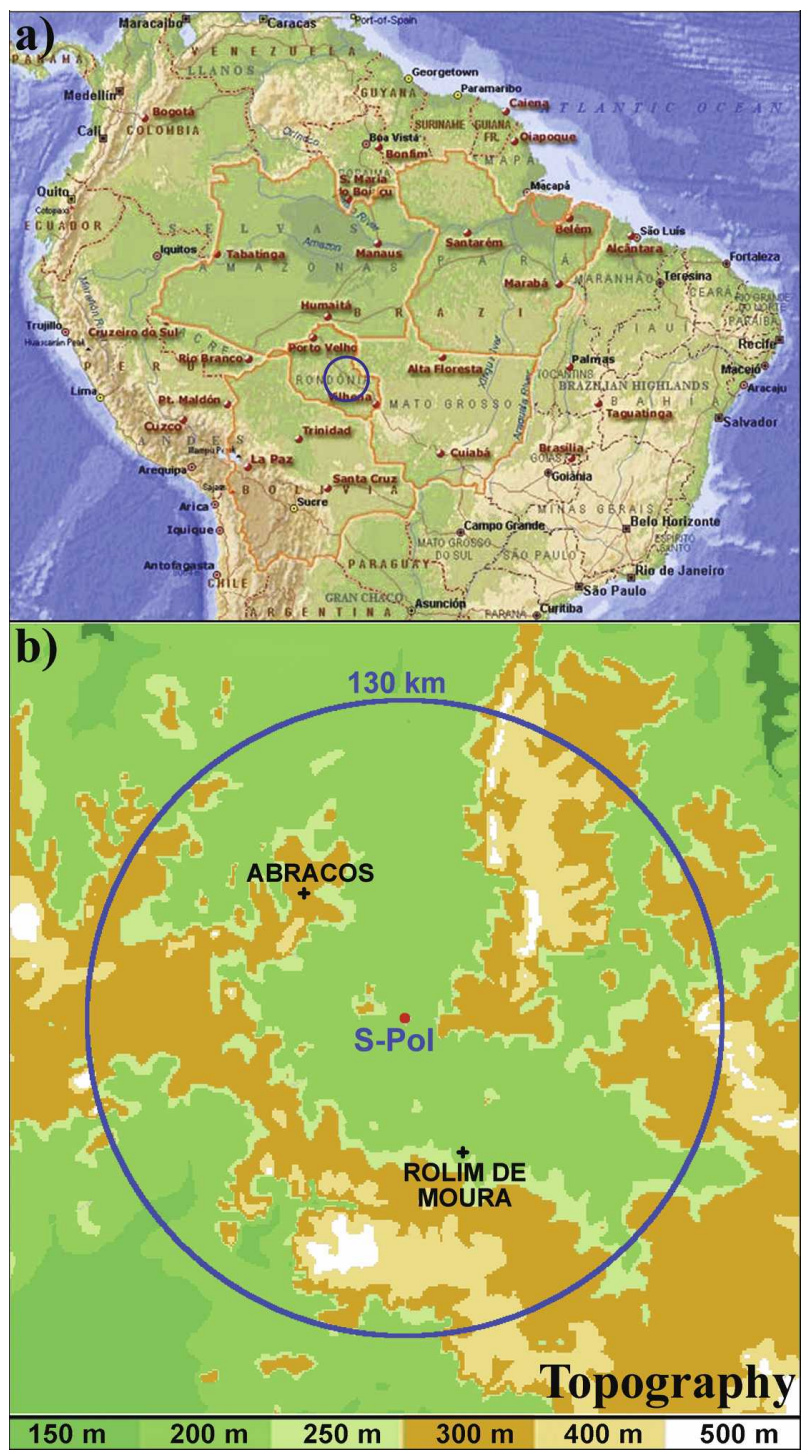

FIG. 1. (a) Experimental area of study: Rondônia, Brazil. The circle shows the $130-\mathrm{km}$ range ring (radius) around S-Pol; (b) topography surrounding the S-Pol radar and the location of the sounding site (Abracos) and the surface weather station (Rolim de Moura) used in the paper.

that were associated with circular cloud rings. Circular cloud rings are observed in the United States, particularly in the southeast, but with much less frequency than over the Amazon. The recent Rain in Cumulus over Oceans (RICO) field campaign in the Caribbean frequently observed arcs of cumulus clouds apparently associated with cold pools that were responsible for most of the observed precipitation (Snodgrass 2006). Tompkins (2001) utilizing a high-resolution cloudresolving model simulated convection over the tropical ocean under very low-shear conditions. In a similar manner to that reported in this paper the simulated 
initial storms produced circular cold pools that initiated new storms along the leading edge of the cold pools. In addition Khairoutdinov and Randall (2006) conducted a modeling study for a case during TRMM-LBA that produced circular cold pools that initiated storms. This is consistent with the modeling findings of Tompkins (2001) and the observations reported in this paper.

While this study only examines in detail the initiation and evolution of convective storms on 1 day during TRMM-LBA, similar evolution was observed on a number of days during the 44-day field project. This study would likely be relevant to any warm moist environment when synoptic forcing is very weak.

Most of the observational studies of convection over the Amazon have been concerned with the large-scale characteristics of the summer month's precipitation. A notable difference in the structure of the convection tends to be associated with oscillations in the largescale circulation during the active and "break" periods of the South American monsoon system (Carvalho et al. 2002; Jones and Carvalho 2002; Petersen et al. 2002).

Data collected during TRMM-LBA (Silva Dias et al. 2002a) have shown that two prevailing regimes existed that could be defined by the $850-700-\mathrm{hPa}$ wind direction: westerly (monsoon) when the flow was predominantly between $270^{\circ}$ and $360^{\circ}$ and easterly (monsoon break) when it was between $45^{\circ}$ and $135^{\circ}$. These observed alternating flow regimes lead to contrasts in local properties of deep convection. During the westerly (easterly) regime, with moister (drier) conditions the convection is characterized by lesser (greater) vertical development, and reduced (enhanced) lightning activity (Cifelli et al. 2002, 2004; Halverson et al. 2002; Laurent et al. 2002; Williams et al. 2002; Albrecht and Silva Dias 2005).

Marengo et al. (2004) using rainfall composites from rain gauge networks found that for both westerly and easterly regimes there is an early afternoon peak in rainfall. Utilizing the National Aeronautics and Space Administration (NASA) Tropical Ocean and Global Atmosphere (TOGA) C-band Doppler radar data and infrared satellite data, Rickenbach (2004) corroborated the above for easterly flow regimes. He also found a secondary nocturnal maximum in cloudiness and precipitation decoupled from the afternoon convective activity. Consistent with the Marengo et al. study, Pereira and Rutledge (2006) utilized the S-Pol radar data to determine that both deep (easterly) and shallow (westerly) convection starts in the morning and peaks in the afternoon. Convection in the easterly regimes showed higher tops, higher rain rates, and larger convective areas.
While the above studies have greatly increased understanding of the general evolution of deep moist convection over the Amazon region, local details of the initiation and evolution have received little attention. There were three studies from TRMM-LBA that did show the importance of the modest terrain over the area. First, Pereira et al. (2000) have shown that during the wet season, deep convection started first over areas with an altitude greater than $300 \mathrm{~m}$ for $70 \%$ of the analyzed days. Second, Laurent et al. (2002) documented the cloud organization using infrared brightness temperature and radar reflectivity over a $5^{\circ}$ square centered on the TRMM-LBA area. The initiation of mesoscale convective systems occurred preferentially over hilly regions with an average terrain height between 250 and $400 \mathrm{~m}$. Third, a model simulation of a TRMM-LBA case by Silva Dias et al. (2002b) pointed out the strong impact of topography and land cover on convective storm evolution for an environment with very weak large-scale forcing.

The objective of this study is to better understand the local influences on thunderstorm initiation and evolution with emphasis on the role of topography and nearsurface cold pools produced by precipitation-driven downdrafts. Inspection of radar and visible satellite imagery for the TRMM-LBA period and subsequent monitoring of satellite imagery over the region, suggest that the general behavior shown in this case study seems to be quite common over the Amazon.

\section{Data}

\section{a. TRMM-LBA}

The availability of frequently updated S-Pol radar data and satellite data provided an excellent opportunity to study convective storm initiation and evolution in the Amazon during TRMM-LBA.

The TRMM-LBA field campaign was carried out in the Amazon from 15 January to 28 February 1999, in parallel with the Wet Season component of the Amazon Mesoscale Campaign (WETAM) of the LBA. The goal of TRMM-LBA was to improve the understanding of atmospheric processes in the Amazon with a focus on the surface-atmosphere processes at different space and time scales. A detailed description of the field campaign is found in Silva Dias et al. (2002a).

Supplemental observations collected during TRMMLBA used in this study are the NCAR S-Pol radar, the satellite imagery, the five atmospheric sounding sites, and the surface station at Rolim de Moura (locations shown in Fig. 1).

The study area for this paper is defined as within 130 
$\mathrm{km}$ of the S-Pol radar. The topography in the study area ranges from 100 to $600 \mathrm{~m}$. The landscape is dominated by the Ji-Paraná River basin and two ranges of hills; one northeast of the radar oriented north-south and the other oriented northwest-southeast south of the radar. Tropical forests cover the area with numerous clear-cut areas used for cattle grazing and farming (Ballester et al. 2003).

\section{b. Satellite data}

During the TRMM-LBA experiment visible images $(0.62 \mu \mathrm{m})$ from the Geostationary Operational Environmental Satellite-8 (GOES-8) satellite were available every $30 \mathrm{~min}$ with a resolution of $1 \mathrm{~km}$ at nadir. Scans started 15 and 45 min after the hour with the study area being scanned approximately 10-11 min later than the start time (Johnson et al. 1994). Thus, the satellite times referred to in this paper are the start time plus $10 \mathrm{~min}$.

\section{c. Radar data}

The radar data used in this study were low-level reflectivity scans from the NCAR S-Pol dual-polarized, S-band radar (Keeler et al. 2000). During the campaign, low-level $360^{\circ}$ scans at elevation angles of $0.7^{\circ}$ and $1.1^{\circ}$ were obtained every $10 \mathrm{~min}$ out to a range of $150 \mathrm{~km}$. These surveillance scans were used to identify atmospheric boundary layer features associated with clearair returns such as gust fronts. Boundary layer convergence lines appear as thin lines of enhanced radar reflectivity. The radar was also used to detect cumulus clouds in their early development stage prior to precipitation. The S-Pol radar operating in other field experiments has demonstrated that it has the capability of detecting nonprecipitating clouds from Bragg scattering (Knight and Vivekanandan 2002).

Somewhat surprisingly, boundary layer clear-air echoes in the Amazon are relatively weak $(<5 \mathrm{dBZ})$ or absent, compared to many other locations in the world. Previous studies (Wilson et al. 1994) and experience have indicated that microwave scattering from insects is the typical source of boundary layer clear-air return. We speculate that the relatively weak return from insects in this area is a result of the insects mostly remaining below the forest canopy $(\sim 30 \mathrm{~m})$, which is below the radar beam.

Because of the weak insect return, radar identification of gust fronts often relied on detecting the line or ring of cumulus clouds that accompanied the gust fronts. Figure 2 is an example of the close correspondence between the satellite visible and radar reflectivity observations of a cumulus cloud ring. In Fig. 2 the visible cumulus cloud is outlined by a white contour (albedo of $15 \%$ ) and is overlaid on the radar reflectivity

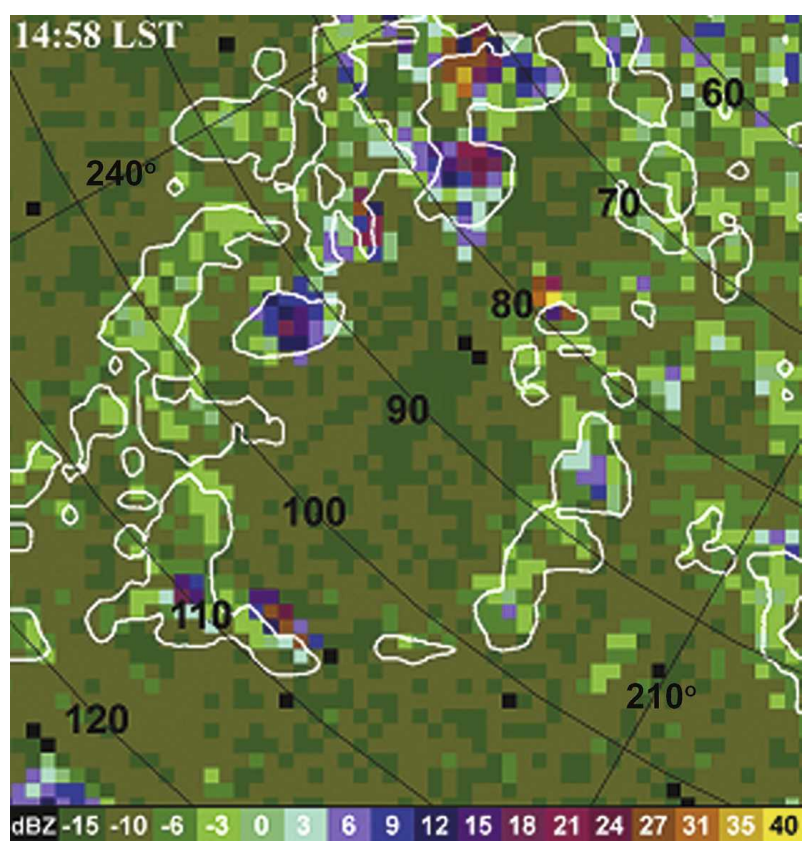

FIG. 2. Comparison of radar reflectivity and visible satellite observations of a cumulus cloud ring at 1458 LST 5 Feb 1999. The white contours represent the satellite albedo value of $15 \%$, which is overlaid on the radar reflectivity ( $\mathrm{dB} Z$ scale across the bottom).

image. Those clouds exhibiting reflectivity $<5 \mathrm{~dB} Z$ are most likely small cumulus that have not developed precipitation size drops (Knight and Miller 1993). There is a reasonably good correspondence between the white satellite contour and radar reflectivity $>-4 \mathrm{dBZ}$.

\section{d. Radar analysis programs}

The Thunderstorm Identification Tracking Analysis and Nowcasting (TITAN; Dixon and Wiener 1993) software was used to identify and track convective storms. The software identifies storms at each time step matching and tracking them in time. For every storm, the area size, peak and average intensity, direction, and speed of motion are recorded. Storm initiation was defined when a convective cell first reached $35 \mathrm{~dB} Z$ over an area of $8 \mathrm{~km}^{2}$. This definition is frequently used for storm designation since reflectivities $>35 \mathrm{dBZ}$ are shown to frequently be associated with lightning (Dye et al. 1989; Gremillion and Orville 1999; Roberts and Rutledge 2003). Although the radar data went out to a range of $150 \mathrm{~km}$, the storm initiation identification process was limited to a radar radius of $130 \mathrm{~km}$. This helped to exclude storms that moved into the radar range.

After the identification of all storms, another software tool recorded the time, latitude, longitude, and the terrain elevation of the initiation location. All data were projected to a common coordinate system and 

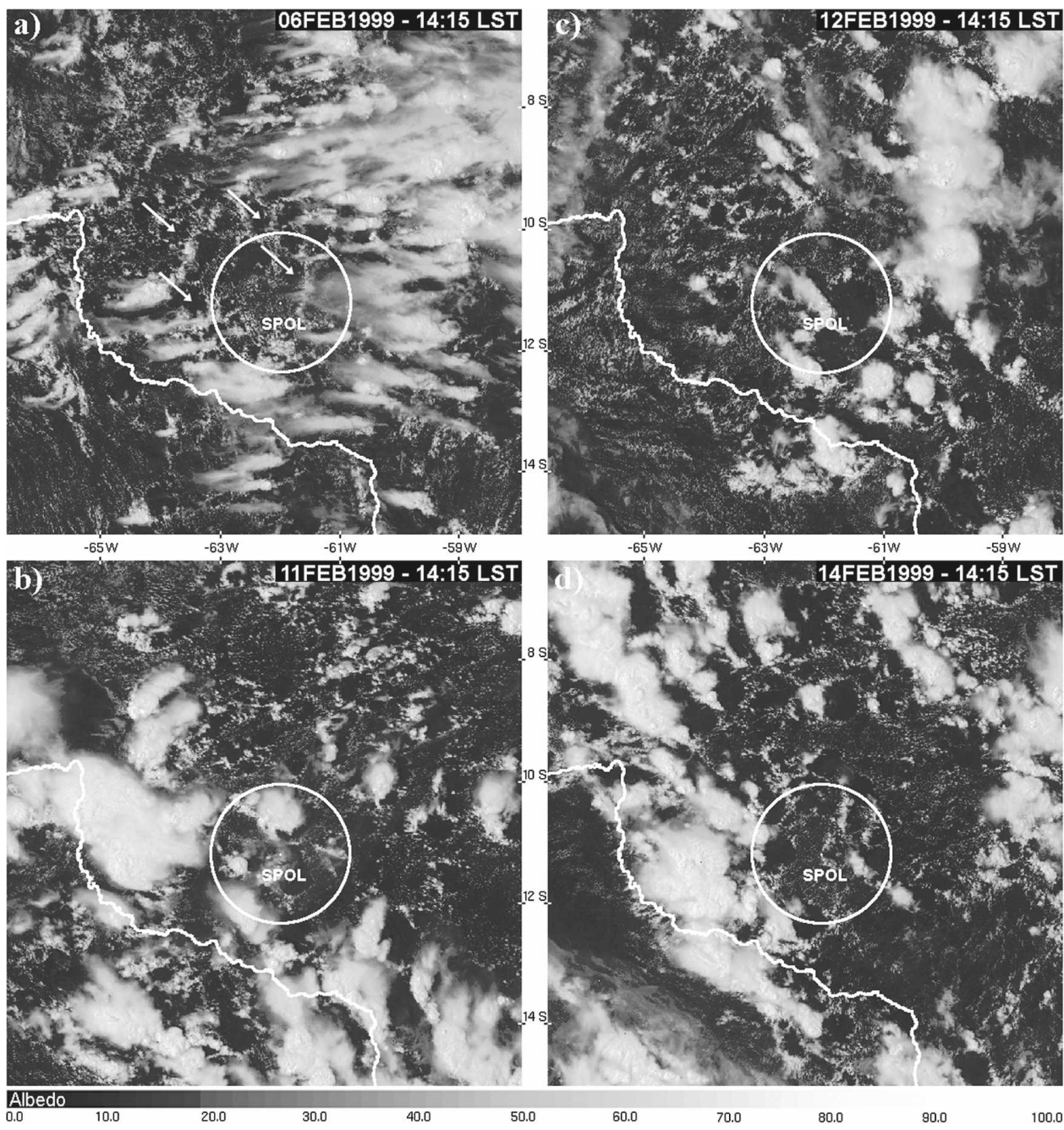

FIG. 3. Examples of cumulus cloud rings over the Amazon for 4 days as seen by GOES-8. (a) The arrows point to a few cloud rings.

displayed on the NCAR display system, the Cartesian Interactive Data Display (CIDD, see online at http:// www.ral.ucar.edu/CIDD).

\section{Cold pools and their evolution}

Examination of the GOES-8 and S-Pol data over the 6-week period of S-Pol collection indicated there was a frequently occurring pattern of unorganized storm initiation in the early afternoon followed by cloud rings that interacted with other cloud rings and initiated other storms. Daily examination of satellite images indicated that $50 \%$ of the days in this 6-week period showed similar cloud rings. Before discussing in the next section a detailed study of storm initiation, it is important to better understand the cloud rings.

While there is insufficient data to examine in detail the dynamical structure and evolution of the cloud rings we are able to provide some insight from time-lapse images of the radar and satellite and observations from a surface station. Figure 3 is an example of cloud rings on 4 different days over Rondônia. It is suspected that many of these cloud rings are the leading edge of cold pools that have been generated from downdrafts and rain-cooled air from earlier showers and thunderstorms. Typically, the interior of the cloud ring is absent of both cloud and any radar echo while the leading edge consists of a ring of cumulus clouds and corresponding radar echo. The ring of clouds is likely in response to the boundary layer convergence and forced updraft by the gust front. The cloud-free region is likely a result of subsidence and lower stability. The absence of radar clear-air return inside the cloud ring is reminiscent of similar observations behind well-defined gust fronts 

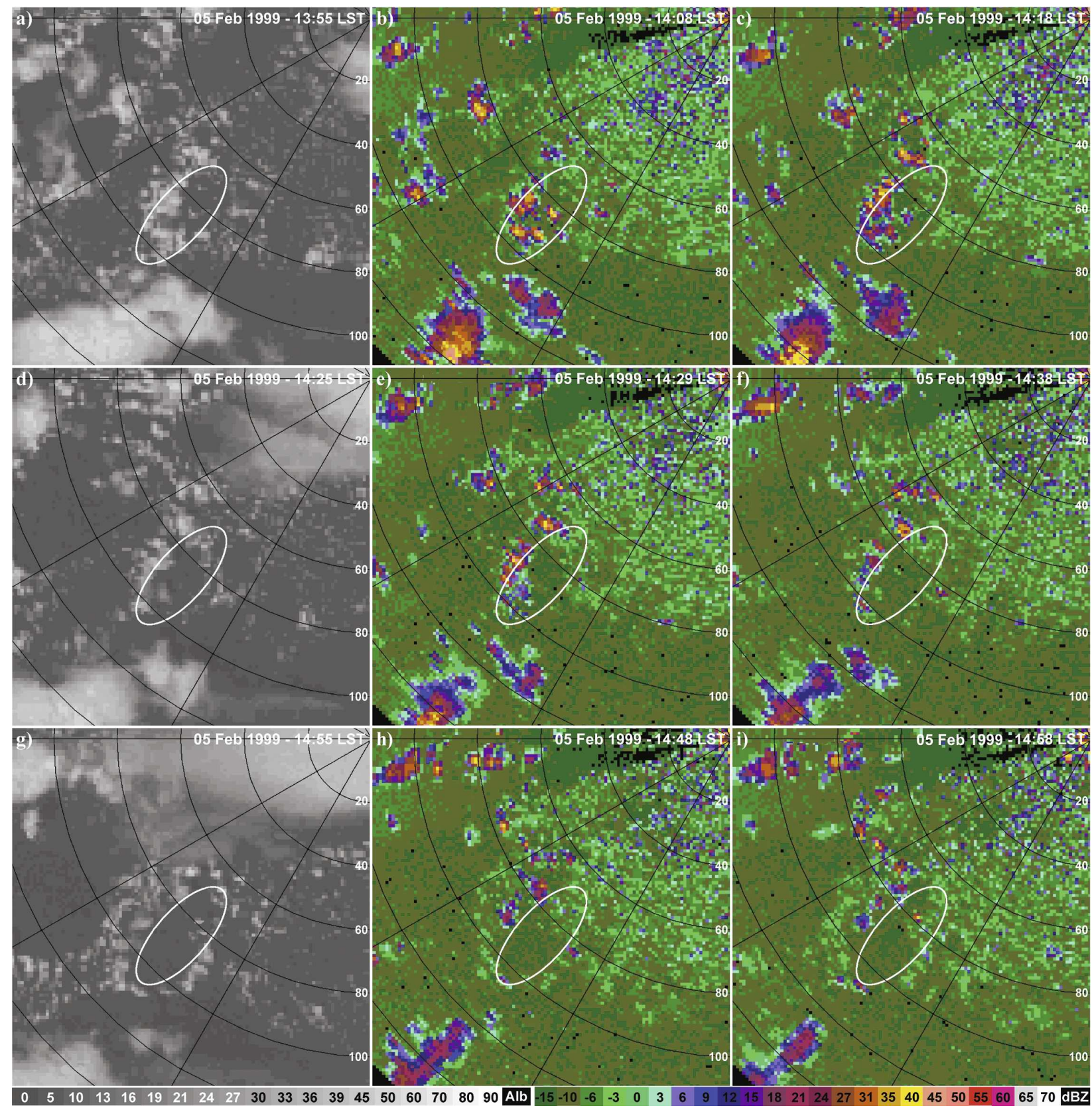

FIG. 4. Development of a cloud ring over an approximately 1-h time period as observed by (middle), (right) S-Pol radar and (left) GOES-8. The white oval represents the cloud ring as observed at 1455 LST by the satellite.

throughout the world. In these cases it has often been assumed that the insects responsible for the clear-air return are absent because of the lack of thermals to lift them to beam height. The lack of thermals behind the gust front is a result of stabilization of the air and subsidence; some evidence for this speculation is provided in Wilson et al. (1994) and the previously mentioned modeling studies by Tompkins (2001) and Khairoutdinov and Randall (2006). Time-lapse images from radar and satel- lite typically show that the cloud rings expand with time, which is suggestive of the expansion of a cold pool.

The development of a cloud ring over an approximate 1-h period is shown in Fig. 4. The white oval in this figure represents the cloud ring at $1455 \mathrm{LST}^{1} 5$

\footnotetext{
${ }^{1}$ Because of the diurnal nature of this study, local standard time will be used, which is UTC $-4 \mathrm{~h}$.
} 
a)

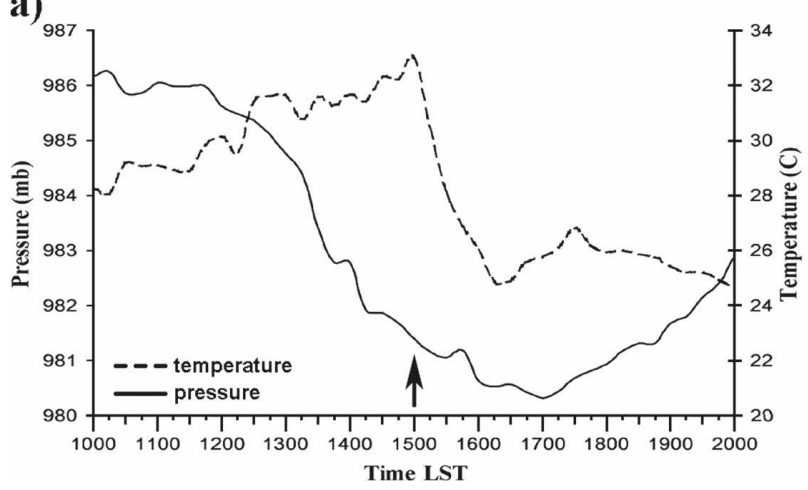

b)

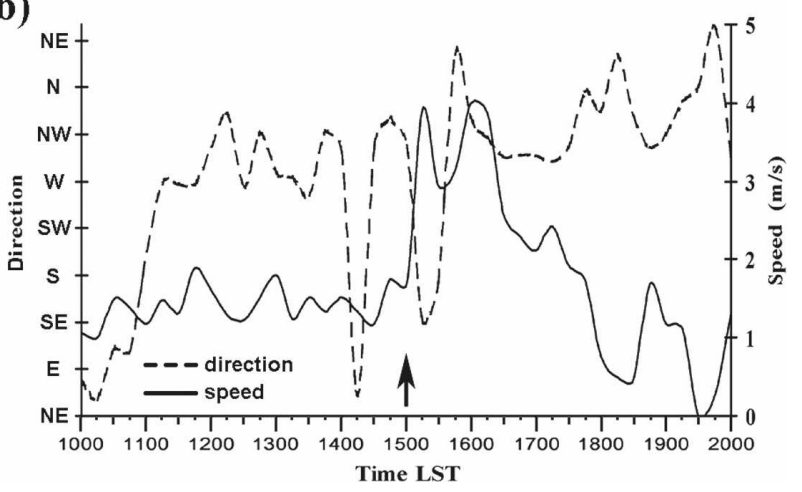

FIG. 5. Time series of (a) temperature and pressure, and (b) wind direction and speed from the surface station Rolim de Moura during the passage of a cloud ring. The arrow denotes the passage time of the GF. No rain was recorded.

February as observed via satellite. Examination of the development of these cloud rings suggests that initially small outflows from individual showers merge resulting in larger cold pools that over a period of about $1 \mathrm{~h}$ form more coherent cloud rings with a long dimension of about $40 \mathrm{~km}$. This sequence of events is very similar to those described in the cloud-resolving model simulation of Khairoutdinov and Randall (2006). In the case of Fig. 4, the convective cells that produced the cloud ring were about $30-40 \mathrm{dBZ}$. It was frequently noted that cells of similar intensity were associated with the cloud rings.

A search for a cloud ring passing over a surface sta- tion resulted in the following two examples. Figure 5 shows a steady $8^{\circ} \mathrm{C}$ drop in temperature over $\sim 70$-min period as a cloud ring on 5 February is observed to move over the surface station called Rolim de Moura. Figure 6 shows the corresponding satellite visual imagery for this case. Another case was observed on 12 February as a cloud ring passed over the same station (not shown). In this case the temperature only dropped $3^{\circ} \mathrm{C}$ when the cold pool first moved over the station, however, later the temperature dropped $9^{\circ} \mathrm{C}$ as a second gust front passed. These examples provide evidence that cloud rings do surround a pool of nearsurface cool air. Strong collaborating evidence is pro-
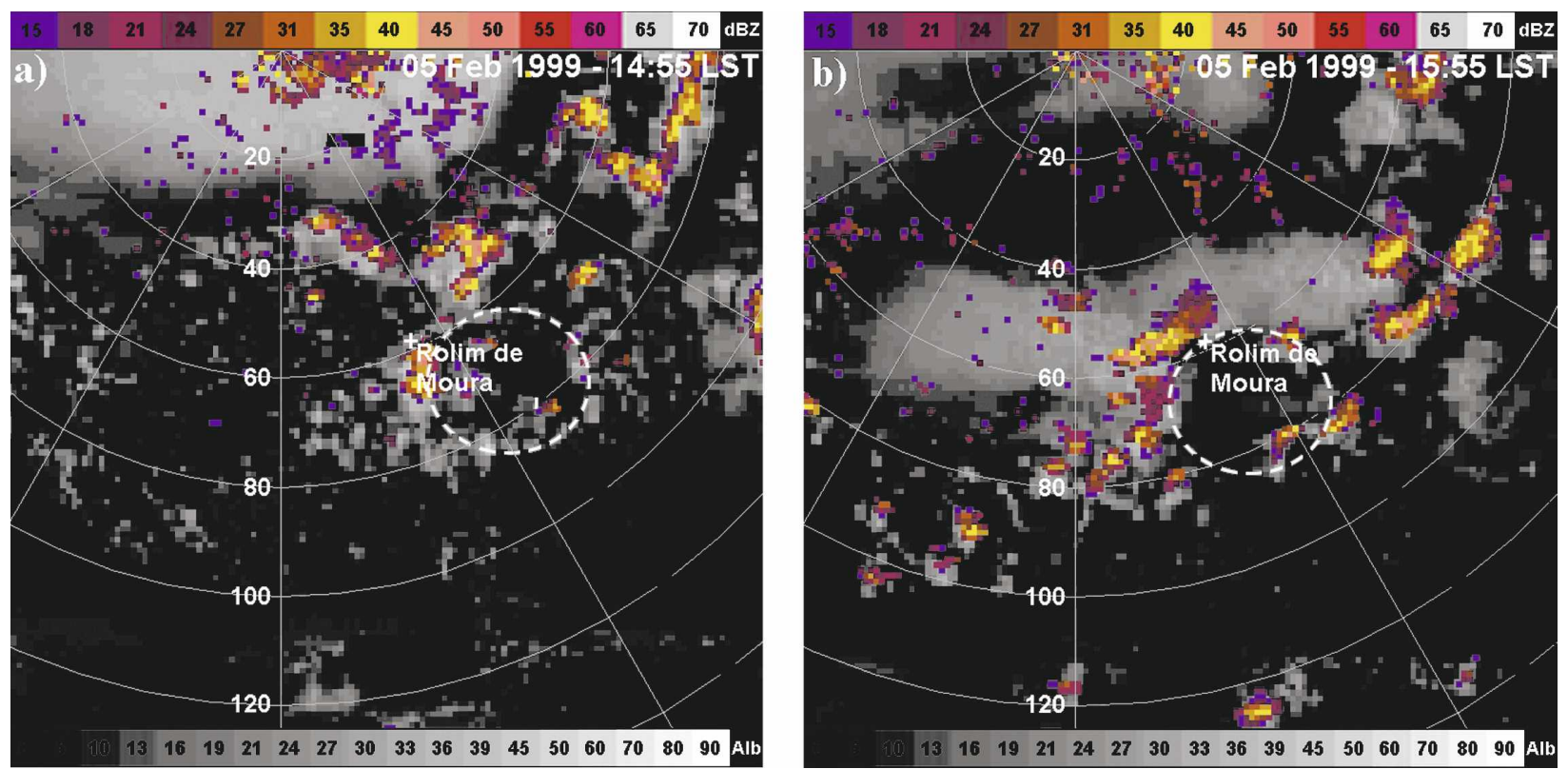

FIG. 6. Satellite imagery at 1455 and 1555 LST showing the cloud ring that passed over surface station Rolim de Moura whose data are shown in Fig. 5. 
vided by the cloud-resolving numerical simulations of Tompkins (2001) for similar low-shear conditions over the tropical ocean. Tompkins (2001) showed the generation of very similar cloud rings surrounding cold pools that were generated from earlier precipitating cumulus. These simulations showed that, on average, the cold pool had a temperature and mixing ratio deficits of $1 \mathrm{~K}$ and $1.5 \mathrm{~g} \mathrm{~kg}^{-1}$ respectively. However, this average only included the initial cold pools prior to subsequent storm initiation and merger with other cold pools.

\section{Storm initiation and evolution}

\section{a. Case selection}

An example of the initiation and evolution of storms on 12 February (one of the days shown in Fig. 3) is shown in Fig. 7. This was a day of minimal large-scale forcing. In Fig. 7a the first convection of the day begins near 1100 LST at scattered locations; subsequent analysis shows these locations are over higher terrain. By 1255 LST (Fig. 7c) several cloud rings are apparent; two of the more dominant are indicated by dashed lines. These cloud rings are observed to expand (Fig. 7e) and eventually collide (Fig. $7 \mathrm{~g}$ ) producing additional storms. In a time period of less than $2 \mathrm{~h}$ these cold pools reached a diameter of about $100 \mathrm{~km}$, which implies a propagation speed of roughly $6 \mathrm{~m} \mathrm{~s}^{-1}$.

The winds on 12 February were very light from the surface up to $300 \mathrm{hPa}$. CAPE was between roughly 1000 and $2000 \mathrm{~J} \mathrm{~kg}^{-1}$ and the convective inhibition (CIN) was $<40 \mathrm{~J} \mathrm{~kg}^{-1}$ depending on estimated surface parcel conditions. Shear values between the surface and $3 \mathrm{~km}$ and surface to $6 \mathrm{~km}$ were very small, around $1 \times 10^{-3} \mathrm{~s}^{-1}$.

To study the initiation and evolution of convective storms due to local influences, it was decided to pick a representative day and record the initiation and evolution of each cell. The chosen day was 5 February. Convective storms developed and dissipated within the SPol range. The synoptic situation over the study area for this day was classified by Marengo et al. (2004) as large-scale subsidence.

On 5 February multiple scattered convective cells began shortly after local noon over the hilly areas $>300 \mathrm{~m}$ in elevation. These showers produced small cloud ringscold pools with horizontal dimensions of only a few kilometers. These small cold pools merged to produce larger coherent cold pools ( $>20-40 \mathrm{~km}$ in diameter), which in turn generated additional clouds and showers. Figure 4 shows the development of a cold pool on this day. During the next few hours scattered cells continued to develop across the region preferentially on the southwest side of the cold pools. Eventually, some of these cells merged and formed small convective lines. Radar observations indicated that the storms decayed gradually after sunset.

\section{b. Environmental conditions}

Figure 8 shows the global analysis from the Centro de Previsão do Tempo e Estudos Climáticos (CPTEC) for 850 and $200 \mathrm{hPa}$ at $1200 \mathrm{UTC}$ (0800 LST). There is an upper-level cyclone circulation over northeastern Brazil and the Bolivian high over northern Argentina. The winds in the study area were very light from the surface to $400 \mathrm{hPa}$. A moist surface layer was overlaid by a slightly drier layer up to $500 \mathrm{hPa}$ (Fig. 9), which was typical from late January to early February (Halverson et al. 2002). In the absence of large-scale forcing, the convection was initiated in response to the diurnal solar heating and local forcing by topography. Shallow cumulus clouds in the morning developed into deep convection during the afternoon. On this day the closest frontal system was along the coast in southeastern Brazil.

Sounding parameters from the 1100 LST Abracos Hill site (Fig. 9) can be considered to represent prestorm conditions. Similar to 12 February the winds are very light from the surface up to $300 \mathrm{hPa}$. CAPE was between 1000 and $2000 \mathrm{~J} \mathrm{~kg}^{-1}$ and the CIN was $<40 \mathrm{~J} \mathrm{~kg}^{-1}$ depending on the estimated surface parcel conditions. Shear values between the surface and $3 \mathrm{~km}$ and surface to $6 \mathrm{~km}$ were very small, around $1 \times 10^{-3} \mathrm{~s}^{-1}$.

\section{c. Classification of the storms' initiation}

During the selected study period, which extended from 1000 to 2400 LST 5 February, a total of 315 storms were initiated in the area of analysis. Each storm initiation was classified according to the physical triggering mechanism as identified using the radar and satellite. The suspected triggering of initiation was classified into four categories: terrain (TF), gust front (GF), colliding boundaries $(\mathrm{CB})$, which in all cases were colliding gust fronts, and unclassified (UC).

\section{1) TERRAin FORCED (TF)}

Storms that initiated at elevations over $300 \mathrm{~m}$, without evidence of other triggering mechanisms, were placed in this category. Figure 10a illustrates that the first clouds observed by satellite are mostly over the higher terrain and Fig. 10b shows that some of the clouds quickly grow into radar echoes in excess of 40 $\mathrm{dB} Z$. 

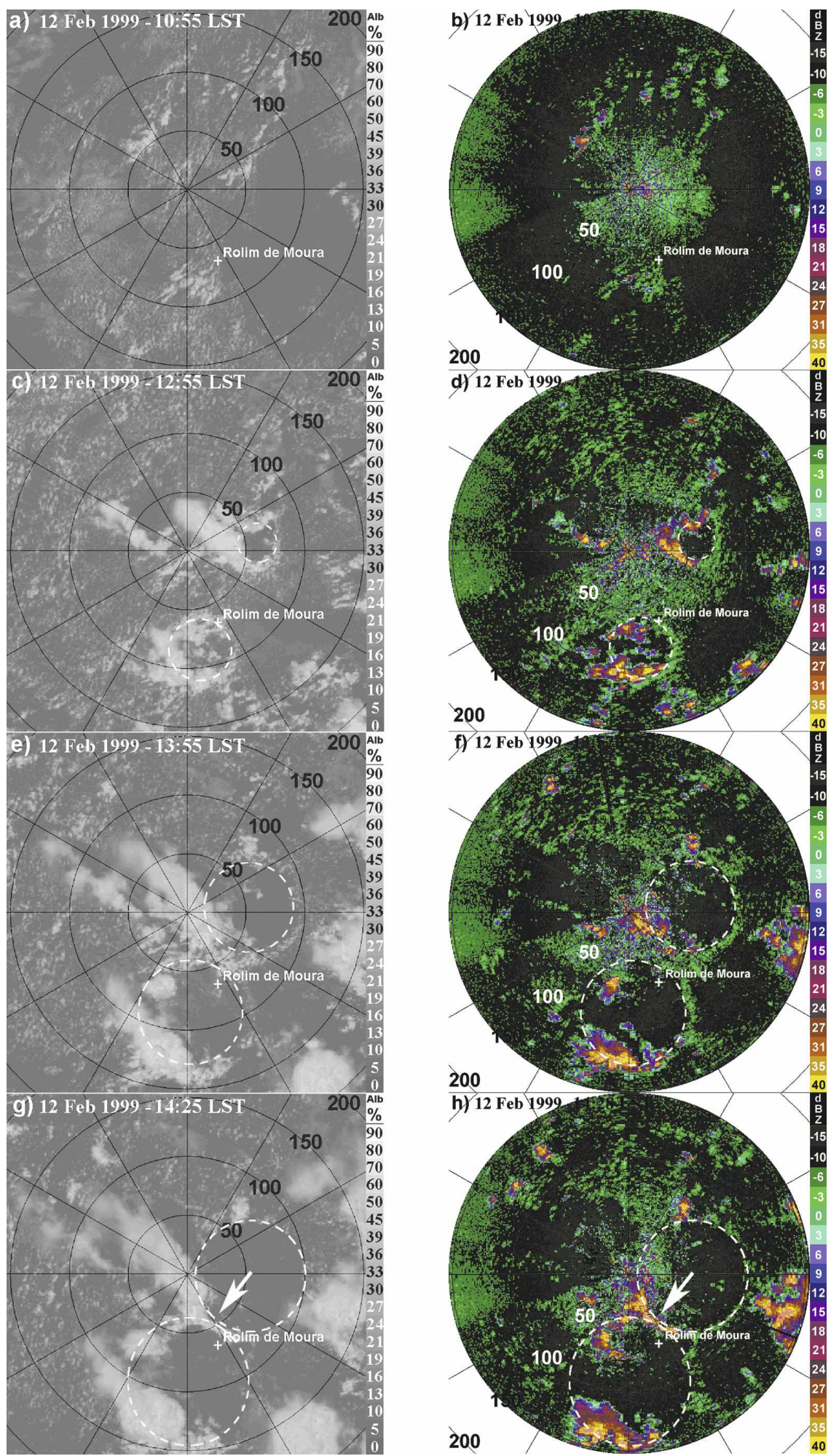

FIG. 7. Evolution of storms and cold pools on 12 Feb 1999 (a) satellite and (b) radar showing the first initiation over higher terrain; (c) satellite and (d) radar showing developing cold pools (white dashed ovals) and GF-initiated storms about $1 \mathrm{~h}$ later than (a), (b); (e) satellite and (f) radar showing expanding cold pools (white dashed ovals) and storms on the southwest side of the cold pools $1 \mathrm{~h}$ later than (c), (d); (g) satellite and (h) radar showing storms (white arrow) that have developed along the collision of the two dissipating cold pools. 

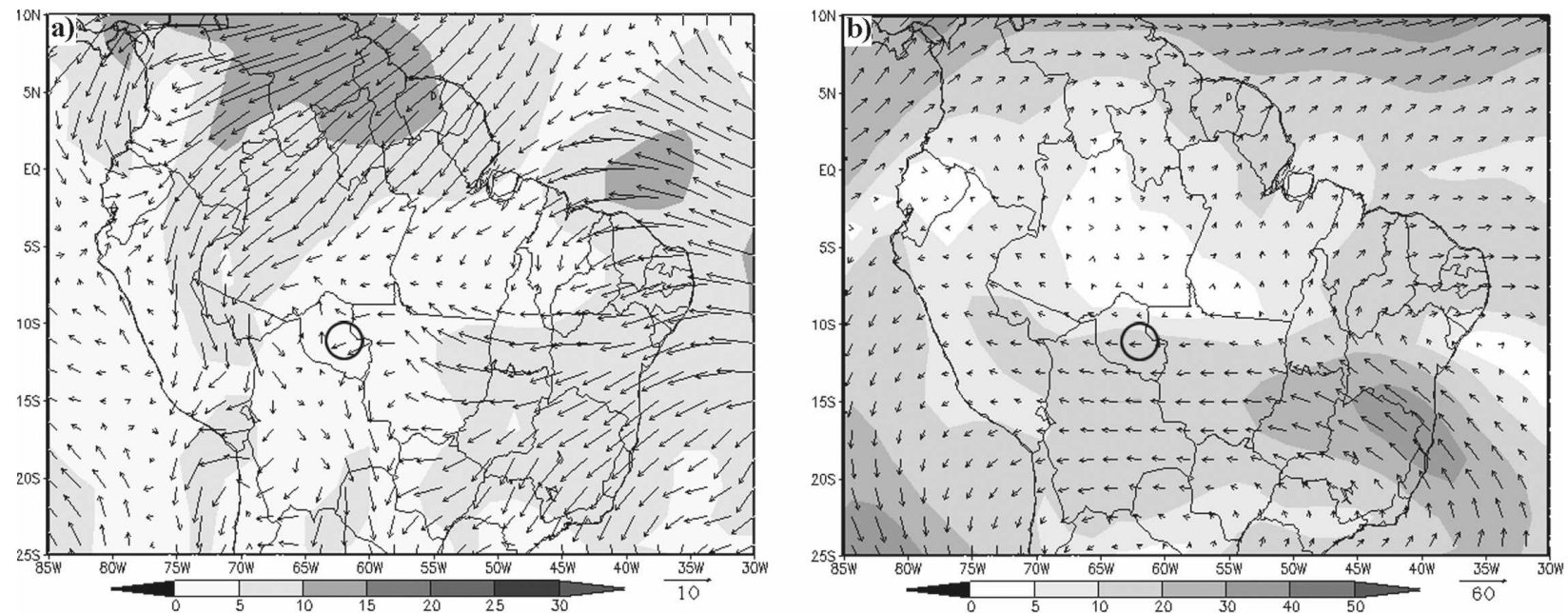

FIG. 8. Winds from the global CPTEC analysis at 1200 UTC 5 Feb 1999: (a) 850 and (b) 200 hPa. Wind speeds are shaded (see scale). The small black circle shows the study area.

\section{2) Gust Front (GF)}

Numerous secondary storms were triggered by outflows (GFs) from storms that initiated over the higher terrain. Storms initiated by GFs whether over terrain above or below $300 \mathrm{~m}$ were placed in this category. Figures 11a,b give an example of this category showing new storms initiated along a GF that was generated by a group of storms southwest of the radar. The GF identification was based on time-lapse observations of radar reflectivity thin lines and satellite observations of cumulus cloud lines emanating from convective cells.

\section{3) Colliding boundaries (CBs)}

New storms initiated by colliding boundaries (GFs) were placed in this category. This category is illustrated with radar and satellite data in Figs. 12a-d. Two cold pools are visible in the radar and satellite data. As the cold pools expand, they collide and a small line of storms can be seen in Figs. 12c,d to form along the collision zone.

\section{4) UNCLASSIFIED STORMS (UCs)}

In this classification neither radar nor satellite images revealed any clear evidence of the triggering mechanism. Many of these cases occurred at radar ranges beyond $100 \mathrm{~km}$ where it was difficult to detect radar thin lines associated with GFs. There were a number of cases entered in this classification where storm initiation occurred in close proximity to an existing line or cluster of storms when no gust front was observed. There may have been a GF but it was not observed by radar or satellite. This category also included cases where cumulus clouds were observed to form over the higher terrain and move over lower terrain before they reached $35 \mathrm{~dB} Z$. It was suspected that in some of these cases small cold pools intercepted these clouds over the lower terrain prior to reaching $35 \mathrm{dBZ}$.

\section{d. Convection initiation triggering}

The time of initiation for all storms during the period of analysis is shown in the histogram in Fig. 13. The

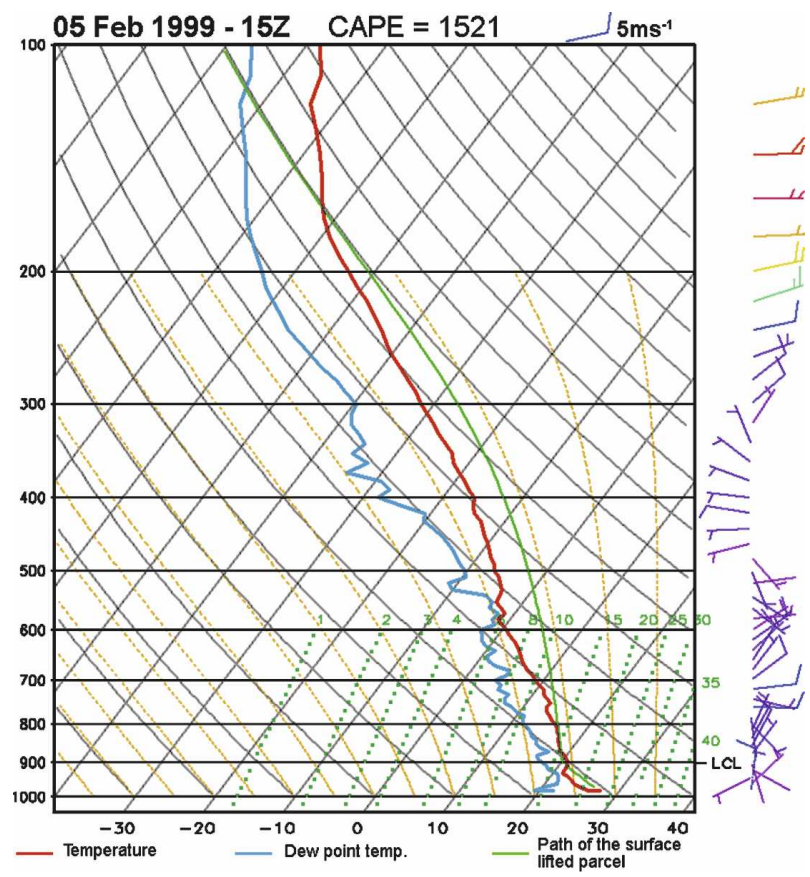

FIG. 9. Sounding from Abracos Hill at 1100 LST (1500 UTC) 5 Feb 1999. Wind barbs are in meters per second. 

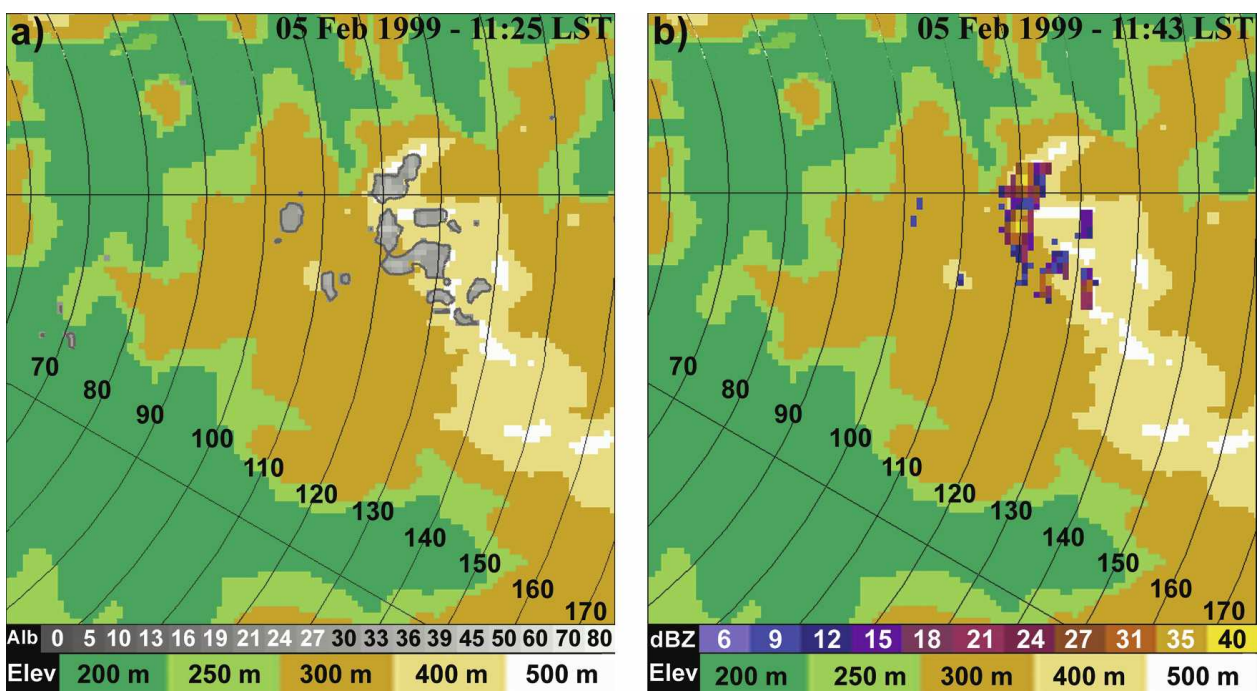

FIG. 10. Example of storm initiation over higher terrain (TF). The terrain (elevation scale at the bottom) is overlaid with (a) the visible image from GOES-8 (gray shading exceeding albedo of $25 \%$ ) and (b) radar reflectivity 18 min later showing that precipitation has developed.

histogram clearly illustrates the diurnal evolution of storm initiation, which begins near noon and rapidly reaches a peak by $1500-1600$ LST. As discussed in section 2 a midafternoon peak in rainfall is typical for the Rondônia region (Marengo et al. 2004).

Figure 14 shows the locations of storm initiation for each hour. The dominance of storm initiation over the higher terrain until 1400 LST is apparent. For the next $2 \mathrm{~h}$ there is considerable initiation over the lower terrain as the GFs reach those locations.

The number of storms initiated by each of the triggering mechanism, defined in section $5 \mathrm{c}$, is shown in
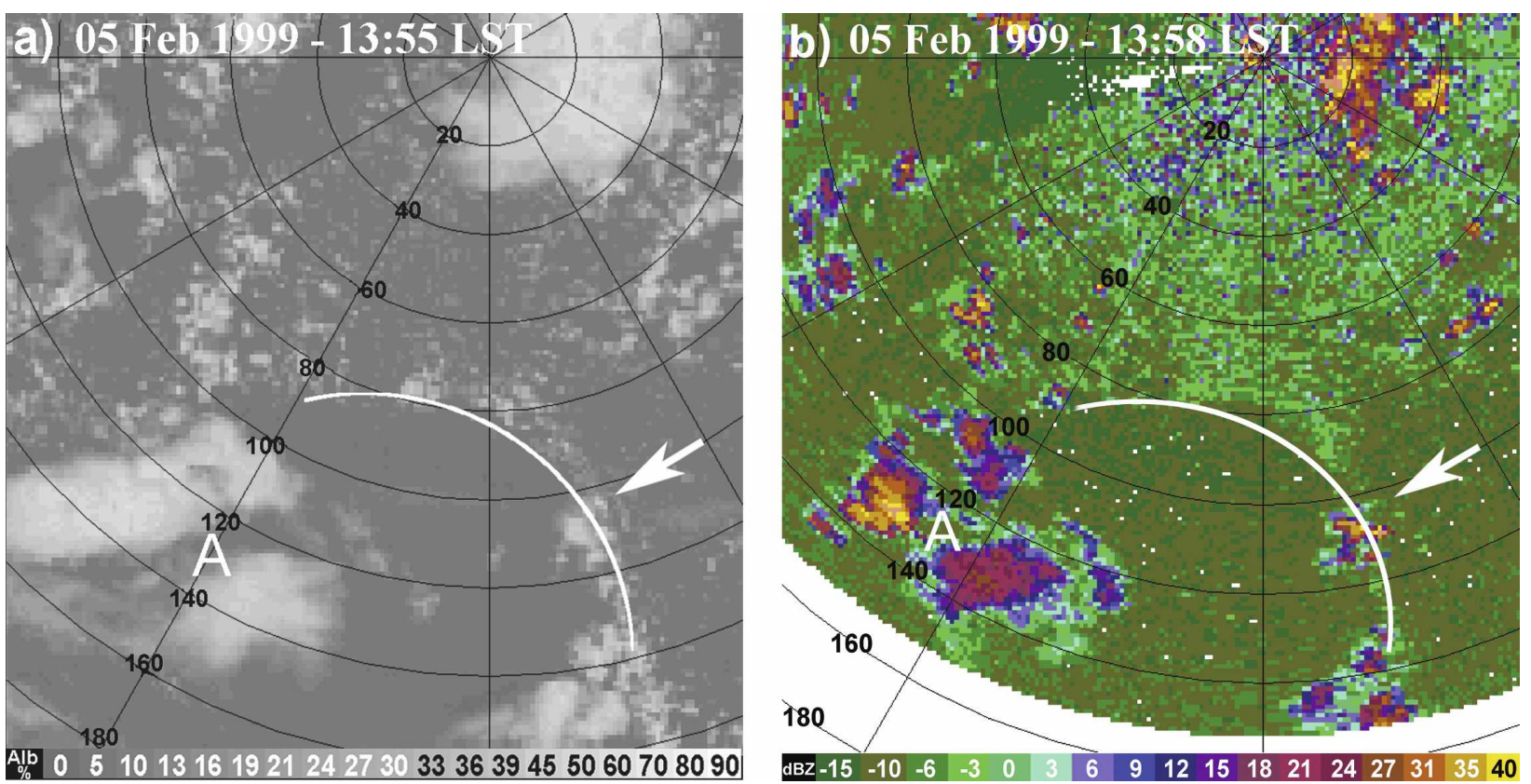

FIG. 11. Example of storms initiated by a GF. (a) Satellite visible image (1355 LST) and (b) reflectivity field (1358 LST) showing the GF (white line) that was generated by the storms in the southwest part of the image (labeled A). The white arrow shows the location of storms developing along the GF. 

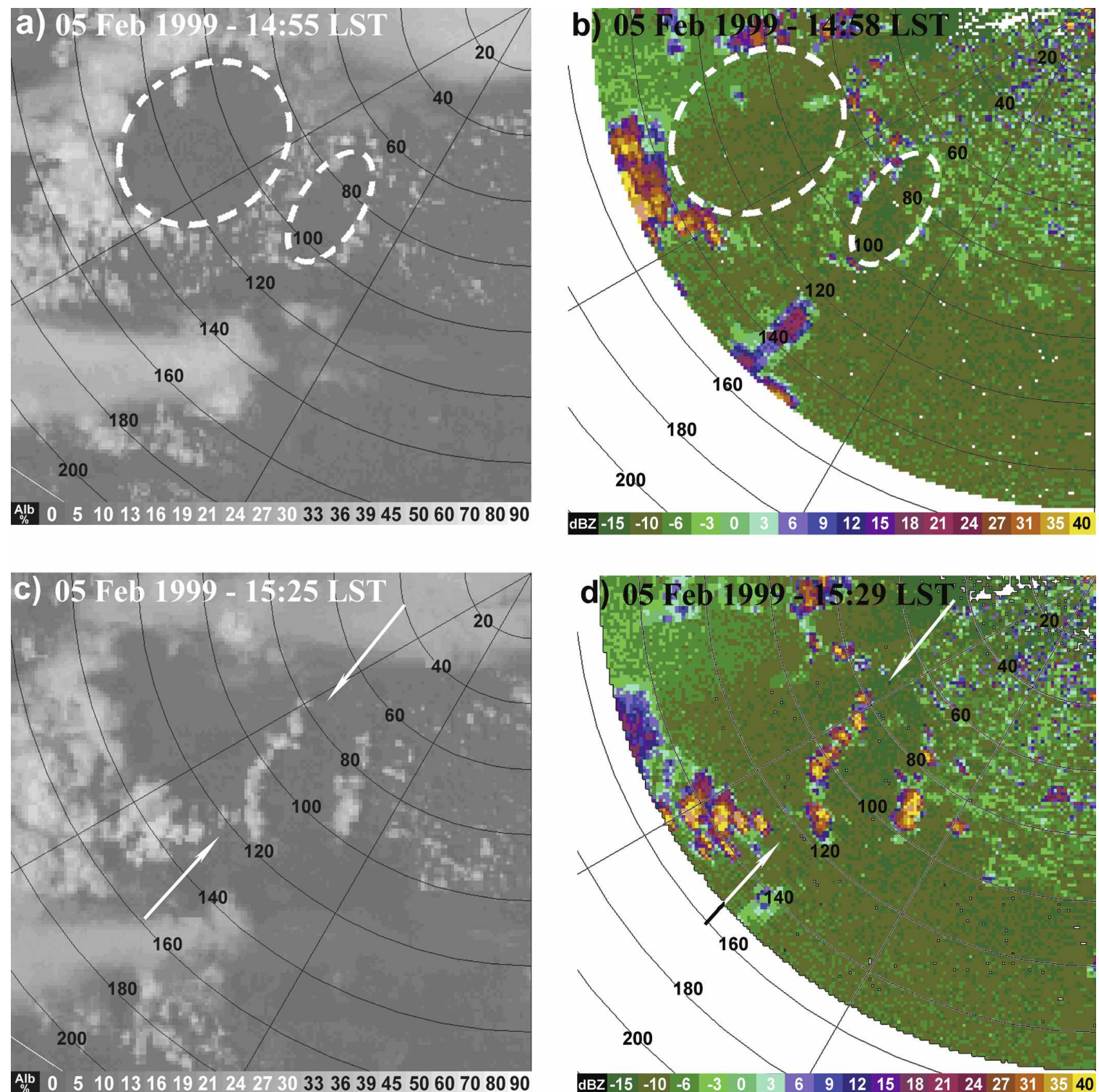

FIG. 12. Example of storm initiation by colliding GFs (CB): (a) visible imagery and (b) radar reflectivity show two cold pools (white dashed ovals) and associated clouds just prior to collision where (c) visible imagery and (d) radar reflectivity show a line of clouds and storms (white arrows) along the collision line.

Fig. 15. The most common initiation mechanisms were by GFs $(36 \%)$, followed by high terrain $(>300 \mathrm{~m})$ without any other triggering mechanism $(21 \%)$ and CBs (16\%). The remaining $27 \%$ were not classified.

The time distribution of triggering by each mechanism is given in Fig. 16. The histograms clearly show that storm initiation was primarily triggered by the higher terrain from 1300 to 1500 LST and then by GFs and colliding GFs the remainder of the afternoon and evening. The secondary peak in initiation over terrain from 1600 to 1700 LST appears to be the result of heating over the higher terrain after the earlier storms moved away. Satellite data shows that for the high terrain south of the radar the skies clear about 1400 LST and that new cumulus begin to grow within 1-2 $\mathrm{h}$ and eventually reach $35 \mathrm{dBZ}$ about 1600 LST. A similar cycle of convective initiation was observed during the North American monsoon in southern Arizona (Zehnder et al. 2006).

\section{e. Storm preferential position}

The examples shown in Figs. 3, 4, 6, and 7 show that the more intense showers and clouds are typically located on the western and southwestern sides of the cold 


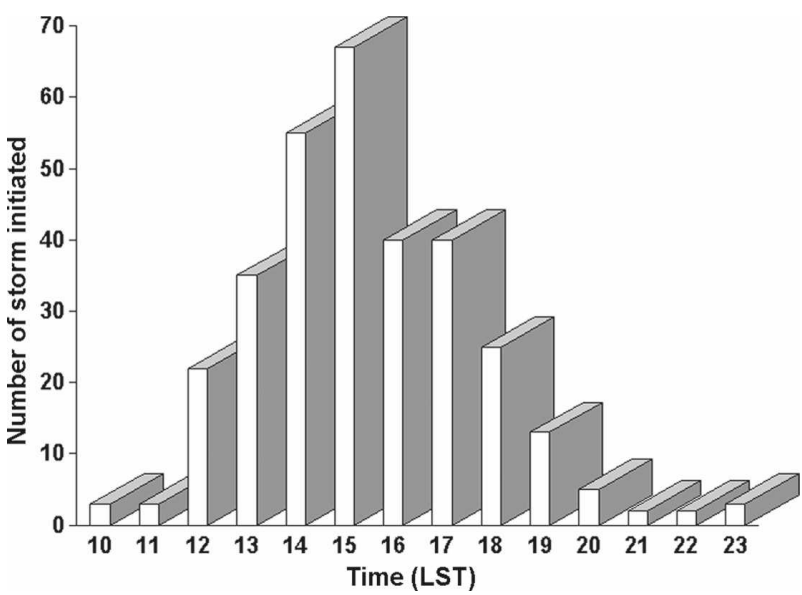

FIG. 13. Number of storm initiations as a function of time (LST).

pools. It is speculated that the reason is similar to the balanced vertical vorticity arguments of Rotunno et al. (1988) and the balanced GF-cell motion arguments of Wilson and Megenhardt (1997). Generally these two arguments produce the same result. With a circular GF, the Rotunno et al. (1988) arguments would indicate that storms would be favored on the side where the vertical shear through the depth of the GF in a vertical plane perpendicular to the GF would produce a counterclockwise rotation in advance of the GF in opposition to the clockwise rotation behind the GF. Typically the shear is computed over the depth of the GF. Radar cross sections (not shown) through four GFs on this day showed the radar thin line to be about 1.0 to $1.5 \mathrm{~km}$ deep. A study by Fisch et al. (2004) indicated a boundary layer depth of $1100 \mathrm{~m}$ for this day. Assuming the GF is $1-1.5 \mathrm{~km}$ deep, the sounding in Fig. 9 shows that the winds are very light and variable becoming northeasterly a few meters per second above $1.5 \mathrm{~km}$. Thus, the winds are so light in this case it is likely the counterclockwise rotation is very weak and may not balance the clockwise rotation produced by the GF at any location around the cold pool but would be most favorable on the southwest side.

The Wilson and Megenhardt (1997) argument states that storm initiation and longer lifetime is favored where the motion of the GF and motion of the convective cell are similar. In this case the southwest quadrant of the GF would be favored; since this portion of the cloud ring is moving toward the southwest at approximately $5 \mathrm{~m} \mathrm{~s}^{-1}$ and the radar echo motion is also about $4 \mathrm{~m} \mathrm{~s}^{-1}$ toward the southwest. This motion is also similar to the storm steering level winds between 850 and $500 \mathrm{mb}$, which are averaging roughly $5-10 \mathrm{~m} \mathrm{~s}^{-1}$ toward the southwest.
To test the speculation that the preferred location of storms is dependent on the direction of the storm steering level winds, a search of all days during the 6-week period was performed to find whether the steering level winds were from a direction other than the northeast quadrant or if clouds and storms were prevalent on a side other than the southwest quadrant. Some cases were found during westerly regimes when the steering winds were westerly and the storm preference was on the easterly side.

\section{f. Representativeness of 5 February}

To obtain a measure of how representative this one study day is of other days during TRMM-LBA all 44 days were examined to determine how storms first appeared in the study area for each day. Also recorded was how the storms evolved during the day. The results are provided in Table 1. Examination of how first storm appeared resulted in four modes: 1) storm initiation along cumulus cloud streets likely associated with horizontal convective rolls, 2) storm initiation over high terrain (category TF in this study), 3) storms that moved into study area, and 4) undefined initiation. Table 1 shows that storm initiation in association with horizontal convective rolls was the most common with $50 \%$ of the days in this category. Nine days each were observed for initiation over higher terrain and for the storms that moved into the study area. For the TRMMLBA period, the first storm initiation over high terrain, as observed on 5 February, accounted for $20 \%$ of the days.

Table 1 shows that cold pools were observed on 20 days. Excluding the nine days when storms moved into the study area circular cold pools occurred in over half the days. Those days when storms moved into the area tended to be associated with mesoscale storm systems where large-scale forcing was presumably relatively strong.

\section{Summary}

It was possible to detect and monitor the full evolution of cumulus clouds, cold pools, and their associated GFs with the NCAR's S-Pol weather radar combined with GOES-8 visible satellite imagery. This study is unique in that it examines in detail the convection initiation triggering mechanism of individual storms for an entire day (5 February). This day is likely representative of many summer days over the Amazon. Storm initiation was defined to occur when the radar reflectivity reached $35 \mathrm{dBZ}$ over an area of $8 \mathrm{~km}^{2}$. There were 315 storm initiations on this day within $130 \mathrm{~km}$ of 

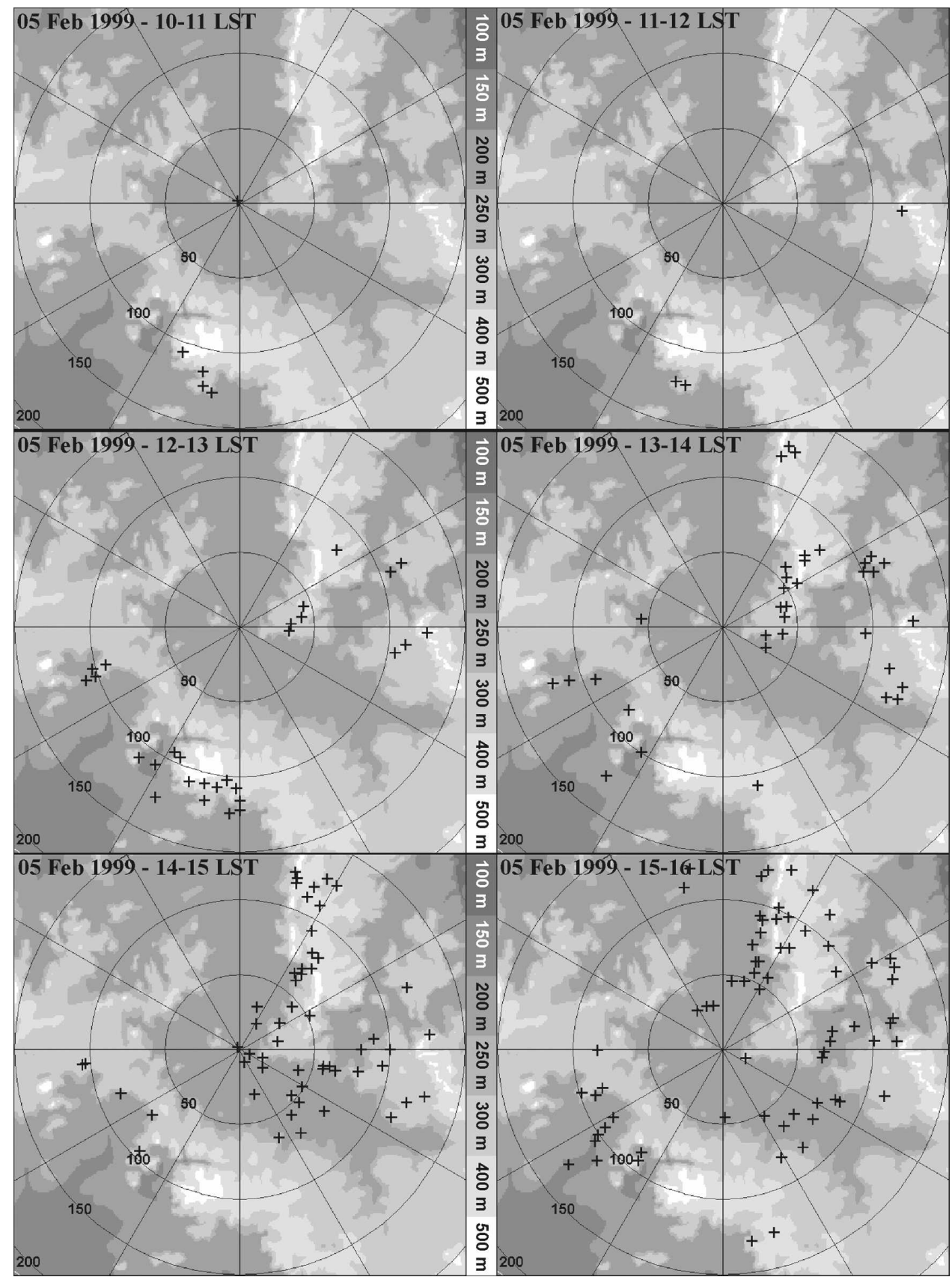

FIG. 14. Location of storm initiations as a function of time. Gray shading refers to elevation.

S-Pol. Storm initiation began around local noon over the higher terrain $(>300 \mathrm{~km})$. Many of these storms generated very small cold pools at the surface, which would merge with others forming larger cold pools with associated near-circular GFs. These GFs would then initiate additional storms preferentially on the southwest quadrant of the ring GF. Toward midafternoon, GFs collided initiating the strongest and longest-lived storms. During the late afternoon, as cooling increased the stability, convection rapidly decreased and ended shortly after sunset.

A conceptual model of storm initiation and evolution is presented in Fig. 17 for storm initiation and evolution over the Amazon for a weak synoptic forcing situation. This model presents two alternatives for first storm initiation, either over high terrain or with horizontal con- 

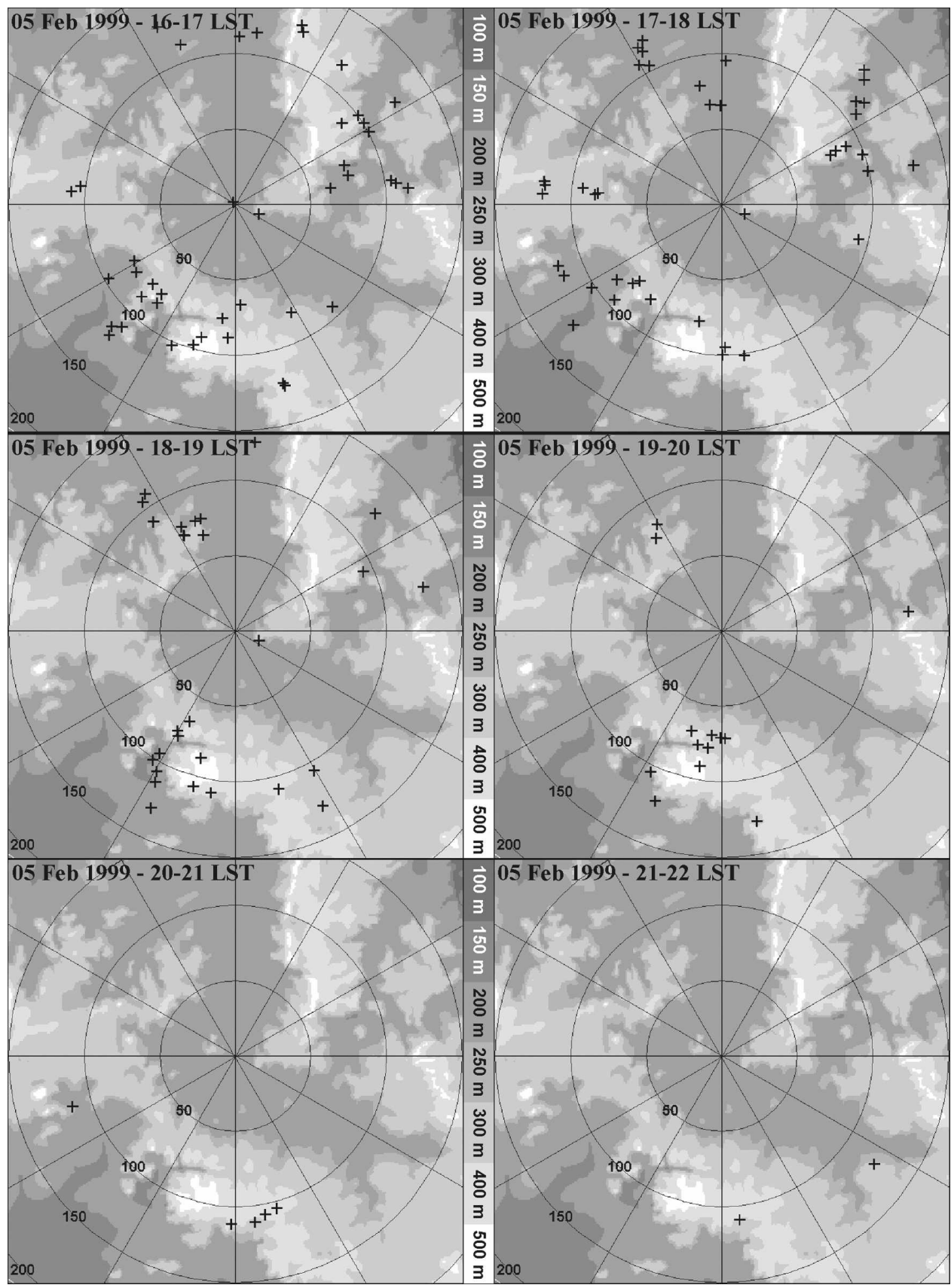

FIG. 14. (Continued)

vective rolls. How representative this model is for the Amazon requires further study. However, cursory examination of satellite data for other years frequently shows circular cloud rings and storm evolution similar to what was observed in this study.

Provided the conceptual model for storm initiation and evolution presented here has broad application to the Amazon region it is then important for numerical models to resolve these very small-scale processes if they are to suitably represent the location, timing, and intensity of the convection. Proper representation of cold pools in numerical models has been shown to be essential for an accurate prediction of deep convective events, especially when synoptic-scale forcing is not strong (e.g., Stensrud and Fritsch 1994; Stensrud et al. 1999). Thus, numerical models must either explicitly resolve cold pool circulations or effectively parameterize their effects. 


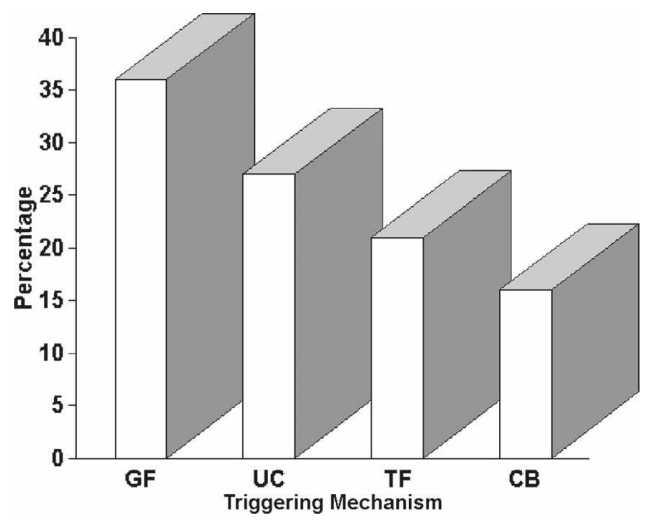

FIG. 15. Percentage of storm initiations caused by each of the triggering mechanisms: $\mathrm{GF}, \mathrm{TF}, \mathrm{CB}$, and $\mathrm{UC}$.

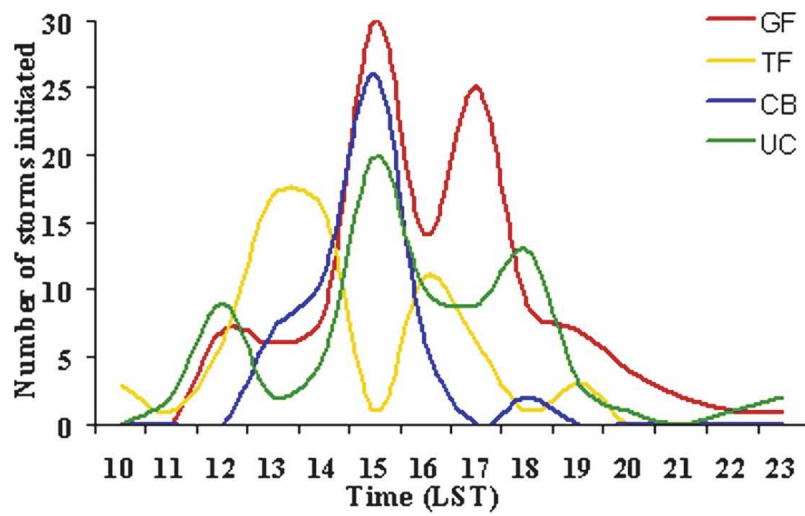

FIG. 16. Number of storm initiations as a function of time (LST) for GF, TF, CB, and UC.

TABLE 1. Triggering mechanisms of the first storm initiation and the resulting storm evolution for the 44 days of TRMM-LBA.

\begin{tabular}{cc}
\hline How storms first initiated & Resulting storm's pattern \\
\hline $\begin{array}{l}\text { Cumulus clouds aligned in } \\
\text { cloud streets: } 22\end{array}$ & $\begin{array}{l}\text { Short lines: } 9 \\
\text { Storms on favorable side of cold } \\
\text { pools: } 11\end{array}$ \\
& Long lines: 2 \\
Formed over high terrain: 9 & Short lines: 2 \\
& Storms on favorable side of cold \\
& pools: 7 \\
Advected into radar range: 9 & Stratiform bands: 1 \\
& Storms on favorable side of cold \\
& pools: 1 \\
& Long lines: 3 \\
& MCS and/or lines formed by \\
& large GF: 4 \\
Short lines: 1 \\
Unidentified mechanism: 4 & Storms on favorable side of cold \\
& pools: 1 \\
& MCS and/or lines formed by \\
& large GF: 2 \\
\hline
\end{tabular}
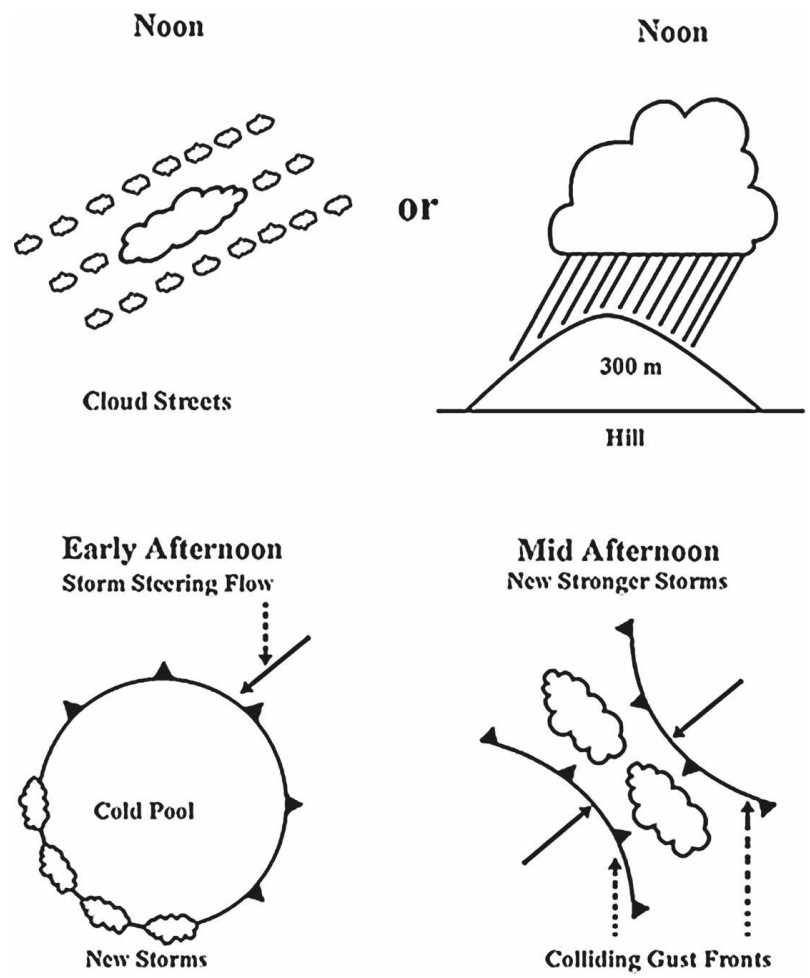

FIG. 17. Conceptual model of storm initiation and evolution over the Amazon for weak synoptic forcing situations. Two separate mechanisms for first storm initiation are provided.

Acknowledgments. The authors thank Paul Hein of CSU for providing the GOES-8 data and Bob Rilling and Chris Burghard of NCAR for formatting the satellite data for display in Zebra. Niles Oien of NCAR was very responsive in developing software to display storm initiation locations in CIDD and general support of analysis programs at IPMET. Carlos Antonio of IPMET did an excellent job of preparing the figures. We thank Rita Roberts of NCAR who provided an excellent review of an earlier version of the paper that led to substantial revisions and improvements. Thanks to Bart Geerts and other formal reviewers of the paper who also helped to improve the paper. We also appreciate the helpful discussions with M. A. F. Silva Dias. The NCAR S-Pol crew, Mike Strong, Joe Vinson, Tim Rucker, Kurt Knudson, Don Ferraro, and Jon Lutz, did an excellent job setting up and operating S-Pol in a challenging remote environment. None of this would have been possible without Steve Rutledge of Colorado State University, who was the lead principal investigator for the successful proposal to deploy S-Pol to Brazil.

\section{REFERENCES}

Albrecht, R. I., and M. A. F. Silva Dias, 2005: Microphysical evidence of the transition between predominant convective/ 
stratiform rainfall associated with the intraseasonal oscillation in the southwest Amazon. Acta Amazonica, 35, 175-184.

Ballester, M. V. R., and Coauthors, 2003: A remote sensing/GISbased physical template to understand the biogeochemistry of the Ji-Paraná river basin (western Amazonia). Remote Sens. Environ., 87, 429-445.

Banta, R. M., and C. B. Schaaf, 1987: Thunderstorm genesis zones in the Colorado Rocky Mountains as determined by traceback of geosynchronous satellite images. Mon. Wea. Rev., 115, 463-476.

Betts, A. K., and C. Jakob, 2002: Study of diurnal cycle of convective precipitation over Amazonia using a single column model. J. Geophys. Res., 107, 4732, doi:10.1029/2002JD002264.

Carvalho, L. M. V., C. Jones, and M. A. F. Silva Dias, 2002: Intraseasonal large-scale circulations and mesoscale convective activity in tropical South America during the TRMMLBA campaign. J. Geophys. Res., 107, 4309, doi:10.1029/ 2001JD000745.

Cifelli, R., W. A. Petersen, L. D. Carey, and S. A. Rutledge, 2002: Radar observations of the kinematic, microphysical, and precipitation characteristics of two MCSs in TRMM-LBA. $J$. Geophys. Res., 107, 8077, doi:10.1029/2000JD000264.

—, L. D. Carey, W. A. Petersen, and S. A. Rutledge, 2004: An ensemble study of wet season convection in southwest Amazonia: Kinematics and implications for diabatic heating. $J$. Climate, 17, 4107-4124.

Dixon, M., and G. Wiener, 1993: TITAN: Thunderstorm Identification, Tracking Analysis and Nowcasting-A radar-based methodology. J. Atmos. Oceanic Technol., 10, 785-797.

Dye, J. E., W. P. Winn, J. J. Jones, and D. W. Breed, 1989: The electrification of New Mexico thunderstorms. Part I: Relationships between precipitation development and the onset of electrification. J. Geophys. Res., 94, 8643-8656.

Fisch, G., J. Tota, L. A. T. Machado, M. A. F. Silva Dias, R. F. da F. Lyra, C. A. Nobre, A. J. Dolman, and J. H. C. Gash, 2004: The convective boundary layer over pasture and forest in Amazon. Theor. Appl. Climatol., 78, 47-59.

Gremillion, M. S., and R. E. Orville, 1999: Thunderstorm characteristics of cloud-to-ground lightning at Kennedy Space Center, Florida: A study of lightning initiation signatures as indicated by WSR-88D. Wea. Forecasting, 14, 641-649.

Halverson, J. B., T. Rickenbach, and E. Williams, 2002: Environmental characteristics of convective systems during TRMMLBA. Mon. Wea. Rev., 130, 1493-1509.

Johnson, D. B., P. Flament, and R. L. Bernstein, 1994: Highresolution satellite imagery for mesoscale meteorological studies. Bull. Amer. Meteor. Soc., 75, 5-33.

Jones, C., and L. M. V. Carvalho, 2002: Active and break phases in the South American monsoon system. J. Climate, 15, 905914.

Keeler, R. J., J. Lutz, and J. Vivekanandan, 2000: S-Pol: NCAR's polarimetric Doppler radar. Proc. Int. Geoscience and Remote Sensing Symp., Honolulu, HI, IEEE, 1570-1573.

Khairoutdinov, M., and D. Randall, 2006: High-resolution simulation of shallow-to-deep convection transition over land. $J$. Atmos. Sci., 63, 3421-3436.

Knight, C. A., and L. J. Miller, 1993: First radar echoes from cumulus clouds. Bull. Amer. Meteor. Soc., 74, 179-188.

— , and J. Vivekanandan, 2002: First radar echoes and the early $Z_{\mathrm{DR}}$ history of Florida cumulus. J. Atmos. Sci., 59, 1454-1472.

Laurent, H., L. A. T. Machado, C. A. Morales, and L. Durieux, 2002: Characteristics of the Amazonian mesoscale convective systems observed from satellite and radar during the
WETAMC/LBA experiment. J. Geophys. Res., 107, 8054, doi:10.1029/2001JD000337.

Marengo, J. A., G. F. Fish, C. A. Morales, I. Vendrame, and P. C. Dias, 2004: Diurnal variability of rainfall in southwest Amazonia during the LBA-TRMM field campaign of the austral summer 1999. Acta Amazonica, 34, 593-603.

Moncrieff, M. W., C. Liu, and H. Hsu, 2005: Convective dynamics issues at $\sim 10 \mathrm{~km}$ grid-resolution. Proc. Workshop on Representation of Sub-grid Processes Using Stochastic-Dynamic Models, Reading, United Kingdom, ECMWF, 91-105.

Pereira, L. G., and S. A. Rutledge, 2006: Diurnal cycle of shallow and deep convection for a tropical land and an ocean environment and its relationship to synoptic wind regimes. Mon. Wea. Rev., 134, 2688-2701.

_ M. A. F. Silva Dias, A. J. Pereira Filho, and P. T. Matsuo, 2000: Timing of convection initiation during the WETAMCLBA. Abstracts, First LBA Scientific Conf., Brasilia, Brazil, Ministry of Science and Technology, 232.

Petersen, W. A., S. W. Nesbitt, R. J. Blakeslee, R. Cifelli, P. Hein, and S. A. Rutledge, 2002: TRMM observations of intraseasonal variability in convective regimes over the Amazon. $J$. Climate, 15, 1278-1294.

Purdom, J. F. W., 1976: Some uses of high-resolution GOES imagery in the mesoscale forecasting of convection and its behavior. Mon. Wea. Rev., 104, 1474-1483.

— 1982: Subjective interpretations of geostationary satellite data for nowcasting. Nowcasting, K. Browing, Ed., Academic Press, 149-166.

Rickenbach, T. M., 2004: Nocturnal cloud systems and the diurnal variation of clouds and rainfall in southwestern Amazonia. Mon. Wea. Rev., 132, 1201-1219.

Roberts, R. D., and S. Rutledge, 2003: Nowcasting storm initiation and growth using GOES-8 and WSR-88D data. Wea. Forecasting, 18, 562-584.

Rotunno, R., J. B. Klemp, and M. L. Weisman, 1988: A theory for strong, long-lived squall lines. J. Atmos. Sci., 45, 463-485.

Schaaf, C. B., J. Wurman, and R. M. Banta, 1988: Thunderstormproducing terrain features. Bull. Amer. Meteor. Soc., 69, 272 277.

Silva Dias, M. A. F., and Coauthors, 2002a: Clouds and rain processes in a biosphere atmosphere interaction context in the Amazon region. J. Geophys. Res., 107, 8072, doi:10.1029/ 2001JD000335.

— , and Coauthors, 2002b: A case study of convective organization into precipitating lines in the southwest Amazon during the WETAMC and TRMM-LBA. J. Geophys. Res., 107, 8078, doi:10.1029/2001JD000375.

Snodgrass, E. R., 2006: Precipitation characteristics from trade wind clouds during RICO derived from radar, satellite and aircraft measurements. M.S. thesis, University of Illinois at Urbana-Champaign, Urbana, IL, 101 pp.

Stensrud, D. J., and J. M. Fritsch, 1994: Mesoscale convective systems in weakly forced large-scale environments. Part II: Generation of a mesoscale initial condition. Mon. Wea. Rev., 122, 2068-2083.

— tance of cold pools to NCEP mesoscale Eta model forecasts. Wea. Forecasting, 14, 650-670.

Tompkins, A. M., 2001: Organization of tropical convection in low vertical wind shears: The role of cold pools. J. Atmos. Sci., 58, 1650-1672. 
Weckwerth, T. M., 2000: The effect of small-scale moisture variability on thunderstorm initiation. Mon. Wea. Rev., 128, 4017-4030.

Williams, E. R., and Coauthors, 2002: Contrasting convective regimes over the Amazon: Implications for cloud electrification. J. Geophys. Res., 107, 8028, doi:10.1029/2001JD000380.

Wilson, J. W., and W. E. Schreiber, 1986: Initiation of convective storms at radar-observed boundary layer convergence lines. Mon. Wea. Rev., 114, 2516-2536.

, and D. L. Megenhardt, 1997: Thunderstorm initiation, or- ganization, and lifetime associated with Florida boundary layer convergence lines. Mon. Wea. Rev., 125, 1507-1525.

_ , T. M. Weckwerth, J. Vivekanandan, R. M. Wakimoto, and R. W. Russell, 1994: Boundary layer clear-air radar echoes: Origin of echoes and accuracy of derived winds. J. Atmos. Oceanic Technol., 11, 1184-1206.

Zehnder, J. A., L. Zhang, D. Hansford, A. Radzan, N. Selover, and C. M. Brown, 2006: Using digital cloud photogrammetry to characterize the onset and transition from shallow to deep convection over orography. Mon. Wea. Rev., 134, 2527-2546. 